\title{
Are the advantages of the Mediterranean diet transferable to other populations? A cohort study in Melbourne, Australia
}

\author{
Antigone Kouris-Blazos ${ }^{1}$, Charalambos Gnardellis ${ }^{2}$, Mark L. Wahlqvist ${ }^{1}$, Dimitrios Trichopoulos ${ }^{3}$, \\ Widjaja Lukito ${ }^{1}$ and Antonia Trichopoulou ${ }^{2} *$ \\ ${ }^{1}$ Department of Medicine, Monash Medical Center, Clayton, Melbourne, Victoria 3168, Australia \\ ${ }^{2}$ National Centre for Nutrition, National School of Public Health, Leoforos Alexandras 196, Athens 115-21, Greece \\ ${ }^{3}$ Department of Epidemiology, Harvard School of Public Health, Boston, MA 02115, USA
}

(Received 23 July 1998 - Revised 5 February 1999 - Accepted 1 March 1999)

\begin{abstract}
A prospective cohort study, involving 141 Anglo-Celts and 189 Greek-Australians of both sexes aged 70 years or more, was undertaken in Melbourne, Australia. The objective was to evaluate whether adherence to the principles of the Mediterranean diet affects survival of elderly people in developed non-Mediterranean countries. Diet was assessed using an extensive validated questionnaire on food intake. A one unit increase in a diet score, devised a priori on the basis of eight key features of the traditional common diet in the Mediterranean region, was associated with a $17 \%$ reduction in overall mortality (two-tailed $P$ value $0 \cdot 07$ ). Mortality reduction with increasing diet score was at least as evident among Anglo-Celts as among Greek-Australians. We conclude that a diet that adheres to the principles of the traditional Mediterranean diet is associated with longer survival among Australians of either Greek or Anglo-Celtic origin.
\end{abstract}

Mediterranean diet: Cohort study: Elderly

People in the European Mediterranean countries have long life expectancies, as documented from WHO mortality statistics (World Health Organization, 1996). Keys and his colleagues (Keys, 1980) hypothesized that the traditional Mediterranean diet has beneficial effects on a range of diseases, and they provided ecological evidence in support of their hypothesis with respect to CHD. In a recent paper that evaluated the evidence accumulated over the last three decades, Willett (1994) concluded that the traditional Mediterranean diet meets several important criteria for a healthy diet. Direct empirical evidence in support of the beneficial properties of the Mediterranean diet has recently become available. In a cohort study of elderly people in rural Greece we found that a one unit increase in a diet score, devised $a$ priori on the basis of eight desirable key features of the traditional common diet in the Mediterranean region, was associated with a statistically significant $17 \%$ reduction in overall mortality (Trichopoulou et al. 1995b). Results of studies of the Mediterranean diet in Mediterranean populations, however, may be confounded by the likely association of adult diet with early life nutritional patterns and culturespecific psychosocial variables such as social support. Therefore, we undertook a study of similar design in Australia among elderly Anglo-Celts and Greek-Australians with two objectives: (1) to examine whether our results from the study in rural Greece could be replicated in an urban setting in Australia, and (2) to examine whether the apparent benefits of the Mediterranean diet are transferable to population groups with very different dietary habits.

\section{Subjects and methods}

Between January 1990 and December 1992 we recorded the dietary habits, over a period of 1 year, of 189 GreekAustralians (ninety-four males and ninety-five females) and 141 Anglo-Celts (seventy males and seventy-one females) aged 70 years or more residing in Melbourne, Australia. Study subjects were recruited using the telephone directory and the overall response, following telephone contact, was $75 \%$. Non-response levels were similar in the two groups. This method has been described by Rutishauser \& Wahlqvist (1983) and Hage et al. (1990) and has been used to obtain representative samples of ethnic Australians. Representativeness, however, is not a precondition for internal validity in a cohort investigation.

Subjects were defined as Anglo-Celtic if both their maternal and paternal grandparents came from the UK and/or Ireland, and as Greek-Australian if they had been born in Greece or if both their parents had been born in Greece. In April 1996 we ascertained the date of death of the twenty-four Greek and fourteen Anglo-Celtic subjects who had died, and confirmed the survival of the remaining 292. 
Although all death certificates were available, cause of death was not specifically studied, because data were too sparse for examination of cause-specific mortality.

A validated, extensive (250 food items and beverages) food-frequency questionnaire was utilized (Wahlqvist et al. 1995; Kouris-Blazos et al. 1996). This questionnaire was adapted from the Australian Polyp Prevention Project (Macrae et al. 1989; MacLennan et al. 1990) to include Greek foods and dishes (fifty items). The portion sizes of foods consumed were recorded in household measures, natural units (e.g. slices of bread) or in comparison with photographs (MacLennan et al. 1990) which also included Greek dishes (Trichopoulou et al. 1988). Portion sizes depicted in food photographs were based on the results of previous validation studies (MacLennan et al. 1990; Ireland et al. 1994; Trichopoulou et al. 1995a). The frequency of consumption of different food items was subsequently quantified on a weekly basis, while seasonal variation of food intake was accounted for by expressing the approximate number of weeks in which the food items were eaten as a fraction of a year. Intakes in $\mathrm{g} /$ week were calculated by multiplying the serving size $(\mathrm{g})$ by the weekly frequency of intake. These values were then translated into $\mathrm{g} / \mathrm{d}$ and were further adjusted to daily intakes of $10460 \mathrm{~kJ}(2500 \mathrm{kcal})$ for men and $8368 \mathrm{~kJ}(2000 \mathrm{kcal})$ for women. Food items were considered in groups as recommended by Davidson et al. (1979) and used by several investigators, including Trichopoulou et al. (1995a). Nutrient intakes for individual subjects were estimated through an Australian nutrient analysis program (NUTTAB 1991) using Australian food composition tables (Cashel et al. 1988) which were modified to include the nutrient composition of Greek dishes (Trichopoulou, 1992). We also established whether the subjects were current smokers (including those who had stopped smoking within the last 5 years) or non-smokers (including those who had not smoked during the last 5 years).

As in a previous study, which evaluated diet in relation to overall survival in elderly Greeks (Trichopoulou et al. 1995b), we used a composite score to describe the total diet and characterize it in comparison with the traditional Mediterranean diet. The mode of food preparation ('cuisine') could not be accounted for in the calculation of the composite score. We used the food groups recommended by Davidson et al. (1979) except that we combined starchy roots with cereals and did not specifically consider sugars and syrups for which no systematic health implications have been firmly documented beyond their contribution to net energy intake. The traditional Mediterranean diet was also defined in terms of these food groups with the addition of moderate intake of ethanol (Helsing \& Trichopoulou, 1989; Trichopoulou et al. 1994) and, therefore, could be adequately characterized in terms of eight key features: high monounsaturated : saturated fat ratio; moderate ethanol consumption (there were no men who drank more than $60 \mathrm{~g}$ ethanol/d and no women who drank more than $20 \mathrm{~g}$ ethanol/d, so that no study subject could be considered a heavy drinker); high consumption of legumes; high consumption of cereals (including bread and potatoes); high consumption of fruits; high consumption of vegetables; low consumption of meat and meat products; and low consumption of milk and dairy products. We used as cut-off point for all characteristics the corresponding median values specific for each sex. We hypothesized, a priori, that a diet with more of these features would have beneficial health effects whereas a diet with fewer of these features would be less healthy. These considerations are based on the collective epidemiological and biological evidence as summarized in the report of the USA National Academy of Sciences (National Research Council, 1989) and a more recent critical overview (Willett, 1994). In the present study 153 (81\%) GreekAustralians and thirty-nine (28\%) Anglo-Celts were found to have four or more of the desirable dietary characteristics.

The statistical analysis was undertaken by modelling the data through Cox's proportional hazards regression (Breslow \& Day, 1987). Initially, eight Cox's models were developed; these controlled for age at enrolment (in 3-month intervals), sex $(0=$ female, $1=$ male $)$, current smoking status $(0=$ non smoker, $1=$ smoker $)$ and ethnic origin $(0=$ Greek-Australian, $1=$ Anglo-Celtic $)$ and evaluated alternatively the eight individual features of the diet score, adjusted for energy. An additional Cox's model was then developed that controlled for age at enrolment, sex, current smoking status and ethnic origin, and evaluated the total diet score as predictor of the hazard of death. Ageadjusted survival curves by ethnic origin and sex were also plotted (Breslow \& Day, 1987).

\section{Results}

Table 1 shows the distribution of the 330 study participants by ethnic origin, sex, age at enrolment and survival status at the end of follow-up on 15 April 1996. These data serve descriptive purposes and provide an overall indication of study power but they are not directly interpretable because

Table 1. Distribution of study subjects by ethnic origin, sex, age at enrolment and survival status by the end of follow-up

\begin{tabular}{|c|c|c|c|c|c|c|c|c|c|c|c|c|}
\hline Age (years) & \multicolumn{6}{|c|}{ Anglo-Celts } & \multicolumn{6}{|c|}{ Greek-Australians } \\
\hline $70-74$ & 50 & 45 & $90 \cdot 0$ & 43 & 43 & $100 \cdot 0$ & 38 & 35 & $92 \cdot 1$ & 32 & 30 & 93.8 \\
\hline $75-79$ & 12 & 8 & $66 \cdot 7$ & 19 & 18 & 94.7 & 28 & 21 & 75.0 & 27 & 23 & 85.2 \\
\hline $80-84$ & 8 & 7 & 87.5 & 3 & 3 & $100 \cdot 0$ & 19 & 17 & 89.5 & 24 & 22 & 91.7 \\
\hline
\end{tabular}


Table 2. Daily consumption (g, adjusted for energy*) of different types of food constituting eight key features of a diet score, by Anglo-Celts and Greek-Australians living in Melbourne (Mean values and standard deviations)

\begin{tabular}{|c|c|c|c|c|}
\hline \multirow[b]{2}{*}{ Consumption } & \multicolumn{2}{|c|}{$\begin{array}{l}\text { Anglo-Celts } \\
(n 141)\end{array}$} & \multicolumn{2}{|c|}{$\begin{array}{c}\text { Greek-Australians } \\
(n \text { 189) }\end{array}$} \\
\hline & Mean & SD & Mean & SD \\
\hline Vegetables & 346 & 180 & 353 & 147 \\
\hline Legumes & 14 & 18 & 86 & 59 \\
\hline Fruits and nuts & 330 & 188 & 252 & 136 \\
\hline Dairy products & 346 & 173 & 246 & 172 \\
\hline Cereals & 204 & 104 & 261 & 97 \\
\hline Meat and meat products & 151 & 84 & 190 & 79 \\
\hline Ethanol & 8 & 14 & 7 & 12 \\
\hline Monounsaturated: saturated ratio & 0.8 & 0.2 & 1.7 & 0.4 \\
\hline Energy $(\mathrm{kJ} / \mathrm{d})$ & 8765 & 2105 & 8862 & 2251 \\
\hline Energy $(\mathrm{kcal} / \mathrm{d})$ & 2095 & 503 & 2118 & 538 \\
\hline
\end{tabular}

${ }^{*}$ To $10460 \mathrm{~kJ}(2500 \mathrm{kcal})$ for men and $8368 \mathrm{~kJ}$ (2000 kcal) for women.

of confounding, age variation within the 5-year groups, and unspecified time to death among the deceased individuals. The data also indicate that the Greek-Australian cohort was, on average, considerably older than the cohort of Anglo-Celts.

Table 2 presents daily intakes (g) of the seven a priori specified food groups, adjusted for energy intake at $10460 \mathrm{~kJ}(2500 \mathrm{kcal})$ for men and $8368 \mathrm{~kJ}(2000 \mathrm{kcal})$ for women, as well as the dietary monounsaturated: saturated fat ratio and the estimated energy intakes $(\mathrm{kJ})$, among the study participants by ethnic origin. Again, these data are not directly interpretable but provide an insight into the food habits of elderly Anglo-Celts and Greek-Australians. Thus, the Greek-Australians consumed higher quantities of legumes, cereals (including bread), possibly meat and meat products, and certainly monounsaturated fats (essentially olive oil), whereas the Anglo-Celts consumed higher quantities of fruits (but not vegetables) and dairy products.

Greek-Australian men and women had a considerable survival advantage over Anglo-Celts of the same sex, after exact adjustment for age at enrolment. The differences were not statistically significant for either sex but they were compatible with expectations based on official demographic statistics in Australia (Young, 1992): among men the rate ratio comparing Anglo-Celts with Greek-Australians was
2.54 (95\% CI 0.93, 6.90); among women the corresponding rate ratio was $1.56(95 \% \mathrm{CI} 0.43,5.70)$.

Table 3 presents the results from four applications of Cox's proportional hazards model, with age, sex, current smoking status, and total diet score as predictor variables. In one of the models that included all study participants, ethnic origin was also included as a predictor variable. With the exception of age, the conditional associations of the other predictor variables with survival were not statistically significant, but they were all plausible and in the 'expected' directions. Moreover, in the most relevant model (last column in Table 3), the rate ratio for an increment of one unit in the diet score was identical $(0.83)$ to that estimated in a study of similar design in Greece (Trichopoulou et al. 1995 ) and the associated $P$ value was 0.07 (or 0.03 if a one-tail test were to be accepted).

In Table 4, food groups were introduced one by one in place of diet score in models similar to those presented in the last two columns respectively in Table 3. Only for fruits and cereals were the results plausible, consistent and statistically significant or suggestive, whereas intake of olive oil (reflected in the monounsaturated: saturated fat ratio) was a significant predictor of survival only when ethnic origin was not included as an independent predictor in the model.

The age-adjusted survival of individuals with diet score

Table 3. Mortality rate ratio (RR) estimates (and 95\% Cl) derived from Cox's proportional hazards models among Australians by ethnic origin*

\begin{tabular}{|c|c|c|c|c|}
\hline \multirow{2}{*}{$\begin{array}{l}\text { Predictor variable } \\
\text { (category or unit) }\end{array}$} & Anglo-Celts & Greek-Australians & All with ethnic term & $\begin{array}{c}\text { All without ethnic } \\
\text { term }\end{array}$ \\
\hline & $\mathrm{RR}(95 \% \mathrm{Cl})$ & $\operatorname{RR}(95 \% \mathrm{Cl})$ & $\mathrm{RR}(95 \% \mathrm{Cl})$ & $\mathrm{RR}(95 \% \mathrm{Cl})$ \\
\hline Age (1 year) & $1.34(1.18,1.52)$ & $1.04(0.98,1.10)$ & $1.09(1.04,1.15)$ & $1.08(1.03,1.13)$ \\
\hline Sex (female 0 , male 1 ) & $3.80(0.85,7.12)$ & $1.33(0.55,3.21)$ & $1.61(0.78,3.33)$ & $1.56(0.76,3.19)$ \\
\hline Smoking status & & & & \\
\hline (non-smoker 0, smoker 1) & $2.37(0.58,1.18)$ & $1.06(0.34,3.38)$ & $1.49(0.61,3.63)$ & $1.42(0.58,3.44)$ \\
\hline Diet score (1 unit) & $0.73(0.45,1.18)$ & $0.91(0.69,1.21)$ & $0.89(0.71,1.12)$ & $0.83(0.67,1.02)$ \\
\hline $\begin{array}{l}\text { Ethnic origin } \\
\text { (Greek-Australians 0, } \\
\text { Anglo-Celts 1) }\end{array}$ & - & - & $1.83(0.74,4.51)$ & - \\
\hline
\end{tabular}

* Key features of the diet score were adjusted to $10460 \mathrm{~kJ}(2500 \mathrm{kcal})$ for men and $8368 \mathrm{~kJ}(2000 \mathrm{kcal})$ for women. 
Table 4. Mortality rate ratio estimates (and $95 \% \mathrm{Cl}$ ) derived from alternative Cox's models with each of eight key features* replacing diet score

\begin{tabular}{lcc}
\hline $\begin{array}{l}\text { Key features } \\
\text { (category or unit) }\end{array}$ & Rate ratio† $(95 \% \mathrm{Cl})$ & Rate ratio $(95 \% \mathrm{Cl})$ \\
\hline Vegetable intake $(20 \mathrm{~g})$ & $1.02(0.99,1.07)$ & $1.08(1.03,1.13)$ \\
Legume intake $(20 \mathrm{~g})$ & $0.98(0.85,1.14)$ & $0.93(0.82,1.06)$ \\
Fruit and nut intake $(20 \mathrm{~g})$ & $0.95(0.90,0.99)$ & $0.95(0.91,1.01)$ \\
Cereal intake $(20 \mathrm{~g})$ & $0.93(0.86,1.01)$ & $0.92(0.85,0.99)$ \\
Dairy intake $(20 \mathrm{~g})$ & $0.99(0.95,1.02)$ & $0.99(0.96,1.03)$ \\
Meat intake $(20 \mathrm{~g})$ & $0.97(0.89,1.06)$ & $0.96(0.88,1.05)$ \\
Monounsaturated: saturated fat ratio (1 unit) & $0.45(0.12,1.55)$ & $0.45(0.56,0.97)$ \\
Ethanol intake $(10 \mathrm{~g})$ & $0.95(0.73,1.24)$ & $0.98(0.75,1.27)$ \\
\hline
\end{tabular}

${ }^{*}$ Adjusted to $10460 \mathrm{~kJ}(2500 \mathrm{kcal})$ for men and $8368 \mathrm{~kJ}(2000 \mathrm{kcal})$ for women.

† From model including terms for age, sex, smoking status and ethnic origin.

¥ From model including terms for age, sex and smoking status but not ethnic origin.

$\geq 4$ in comparison with that of those with diet score $<4$ was also evaluated among Anglo-Celts, Greek-Australians and all study participants. The mortality rate ratio was 0.36 (95\% CI 0.08, 1.67) among Anglo-Celts, 0.72 (95\% CI $0 \cdot 27,1.88)$ among Greek-Australians, and 0.58 (95\% CI $0 \cdot 30,1 \cdot 12)$ among all participants. In the latter instance the two-tailed $P$ value was $0 \cdot 10$.

\section{Discussion}

This was a prospective cohort investigation with an objectively ascertainable outcome and complete follow-up. With this design, selection and information bias are not important issues. The follow-up period was not very long but this does not compromise validity in dynamic cohorts defined on the basis of steady-state dietary habits. Chance and confounding, however, need to be considered and unavoidable exposure misclassification has a predictable attenuating impact on the effect estimates (rate ratios). There were fewer deaths than expected overall in the study, possibly because mortality is declining in the relevant age groups in Australia and the participating individuals had, in general, a fairly healthy lifestyle; this, however, does not introduce a bias in the comparison of the effects of variable degree of adherence to the principles of the Mediterranean diet. In addition, confounding by psychosocial variables is less likely in the Australian population samples than in samples of people living in their own Mediterranean countries. Nevertheless, the unexpectedly small number of outcome events (thirty-eight deaths) indicates that the findings of the study need to be interpreted with caution. An additional, and not readily addressable, issue is that elderly GreekAustralians may represent a cohort of survivors from the hardships of post-World-War II Greece, with inherently increased longevity potential.

Overall the results are clearly compatible with the hypothesis that a high value for the diet score, which was developed in order to capture the essential principles of the Mediterranean diet (Trichopoulou et al. 1995a), is associated with longer survival. The results also are compatible with what is generally known about the effects on mortality of the other study variables (last two columns in Table 3). Thus, people older by 1 year have a $10 \%$ higher mortality; mortality of men is $60 \%$ higher than that of women; smokers have a $40-50 \%$ higher mortality than non smokers; and elderly Anglo-Celts in Australia have an $80 \%$ higher mortality than Greek-Australians. Moreover, the results with respect to diet score consistently point to the beneficial effects of the Mediterranean diet (Table 3). Indeed, the point estimate for a one unit increment $(0.83$ in the last column model in Table 3 ) is identical to the corresponding point estimate from the earlier study in rural Greece. In contrast, the results presented in Table 4 and focused on the eight individual key features of the diet score are, overall, unremarkable. It appears that: (1) the diet score is a better descriptor of the apparent health effects of diet than any of its individual key features; (2) the principles of the Mediterranean diet, as captured in the diet score, convey lower overall mortality and longer survival; and (3) the apparent benefit of the Mediterranean diet is evident not only among Greek-Australians but also among Australians of Anglo-Celtic origin (Table 3). Among Greek-Australians $81 \%$ had a diet score of 4 or more whereas among AngloCelts only $28 \%$ had a diet score in this range. The mortality rate ratio contrasting people with diet score 4 or more $v$. the remaining study subjects was 0.58 . On the basis of these data the weighted rate ratio among Greek-Australians would be $0.19 \times 1+0.81 \times 0.58=0.66$ whereas among Anglo-Celts the corresponding rate ratio would be $0.72 \times 1+0.28 \times$ $0 \cdot 58=0.88$. Therefore Anglo-Celts, in comparison with Greek-Australians should be expected to have $33 \%$ higher mortality as a result of diet alone. In reality, mortality of Anglo-Celts was higher than that of Greek-Australians by $83 \%$ (third column in Table 3 ). Thus, it would seem that $40 \%$ (that is, 33/83) of the excess mortality of elderly Australians of Anglo-Celtic origin over that of their fellow Australians of Greek origin could be explained in terms of their different dietary habits and specifically the different extent to which they adhered to the traditional Mediterranean diet. This estimate has, of course, a large CI but the unavoidable misclassification in diet assessment is likely to have systematically reduced the estimated attributable fraction.

We conclude that adherence to the principles of the traditional Mediterranean diet, as operationalized in the diet score used, is likely to be associated with lower overall mortality. Moreover, key features of this diet appear to be transplantable to other dietary cultures and cuisines, and may have a substantial beneficial impact on the general mortality of elderly people who have the Westernized 
dietary habits typically encountered among Australians of Anglo-Celtic origin.

\section{References}

Bain C, Macrae FA, Lambert JR, Wahlqvist MC, Selbie L, Brouwer R \& MacLennan R (1990) The Australian Polyp Prevention Project: compliance to randomized dietary intervention. Proceedings of the Nutrition Society of Australia 15, 8087.

Breslow NE \& Day NE (1987) Statistical Methods in Cancer Research. Vol II. The Design and Analysis of Cohort Studies. IARC Scientific Publication no. 82. Lyon: International Agency for Research on Cancer.

Cashel K, English R \& Lewis J (1988) Composition of FoodsAustralia. Canberra: Department of Community Services and Health, Australian Government Printing Services.

Davidson S, Passmore R, Brock JF \& Truswell AS (1979) Human Nutrition and Dietetics, 7th ed. Edinburgh: Churchill Livingstone.

Hage BH-H, Oliver RG, Powles JW \& Wahlqvist ML (1990) Telephone directory listings of presumptive Chinese surnames: an appropriate sampling frame for a dispersed population with characteristic surnames. Epidemiology 1, 405-408.

Helsing E \& Trichopoulou A (editors) (1989) The Mediterranean diet and food culture: a symposium. European Journal of Clinical Nutrition 43, Suppl. 2, 1-92.

Ireland P, Jolley D, Giles G, O'Dea K, Powles J, Rutishauser I, Wahlqvist ML \& Williams J (1994) Development of the Melbourne FFQ: a food frequency questionnaire for use in an Australian prospective study involving an ethnically diverse cohort. Asia Pacific Journal of Clinical Nutrition 3, 19-31.

Keys A (1980) Seven Countries: A Multivariate Analysis of Death and Coronary Heart Disease. Cambridge: Harvard University Press.

Kouris-Blazos A, Wahlqvist ML, Trichopoulou A, Polychronopoulos E \& Trichopoulos D (1996) Health and nutritional status of elderly Greek migrants to Melbourne, Australia. Age and Ageing 25, 177-189.

MacLennan R, Bain C, Macrae F, Gratten H, Battistutta D \& Bokey EL (1990) Design and implementation of the Australian
Polyp Prevention Project. In Frontiers of Gastrointestinal Research, pp. 60-73 [P Rozen, CB Reich and SJ Winawer, editors]. Basel, Switzerland: Karger.

National Research Council (1989) Diet and Health. Implications for Reducing Chronic Disease Risk. Washington, DC: National Academy Press.

Rutishauser I \& Wahlqvist ML (1983) Food intake patterns of Greek migrants to Melbourne in relation to duration of stay. Proceedings of the Nutrition Society of Australia 8, 49-55.

Trichopoulou A (1992) Composition of Greek Foods and Dishes (in Greek and English). Athens: Athens School of Public Health.

Trichopoulou A, Kampman E, Kolias E \& Georga K (1988) A Photographic Method to Estimate Food and Nutrient Intake in Greece - User's Manual. Athens: Department of Nutrition and Biochemistry, Athens School of Public Health.

Trichopoulou A, Kouris-Blazos A, Vassilakou T, Gnardellis C, Polychronopoulos E, Venizelos M, Lagiou P, Wahlqvist M \& Trichopoulos D (1995a) The diet and survival of elderly Greeks: a link to the past. American Journal of Clinical Nutrition $\mathbf{6 1}$, Suppl. 6, 1346-1350.

Trichopoulou A, Kouris-Blazos A, Wahlqvist M, Gnardellis C, Lagiou P, Polychronopoulos E, Vassilakou T, Lipworth L \& Trichopoulos D (1995b) Diet and overall survival in elderly people. British Medical Journal 311, 1457-1460.

Trichopoulou A, Lagiou P \& Trichopoulos D (1994) Traditional Greek diet and coronary heart disease. Journal of Cardiovascular Risk 1, 9-15.

Wahlqvist ML, Hsu-Hage BH-H, Kouris-Blazos A \& Lukito W (editors) (1995) Food Habits in Later Life: A Cross-Cultural Study. Melbourne: Asia Pacific Journal of Clinical Nutrition \& United Nations University Press (CD Rom).

Willett WC (1994) Diet and health: what should we eat? Science 264, 532-537.

World Health Organization (1996) World Health Statistics Annual. Geneva: WHO.

Young C (1992) Mortality, the ultimate indicator of survival: the differential experience between birthplace groups. In Immigrants in Australia: A Health Profile, pp. 34-70 [J Donovan, EM d'Espaignet, C Merton and $\mathrm{M}$ van Ommeron, editors]. Canberra: Australian Government Publishing Service. 